\title{
Inference of a Molecular Defect of Apolipoprotein B in Hypobetalipoproteinemia by Linkage Analysis in a Large Kindred
}

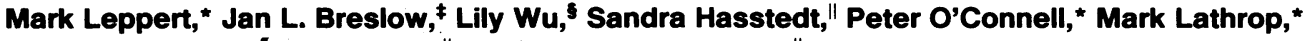 \\ Roger R. Williams,' Ray White, "*\| and Jean-Marc Lalouel*\| \\ ${ }^{*}$ Howard Hughes Medical Institute, University of Utah Medical Center, Salt Lake City, Utah 84132; ${ }^{\ddagger}$ The Rockefeller University, \\ New York, New York 10021; and Departments of ${ }^{\S}$ Pathology, "Human Genetics, and 'Medicine, \\ University of Utah Medical Center, Salt Lake City, Utah 84132
}

\begin{abstract}
Heterozygous hypobetalipoproteinemia is characterized by reduced plasma concentrations of LDL cholesterol, total triglycerides, and apo $B$ to $<50 \%$ of normal values. The molecular basis of this disorder remains unknown. The phenotype cosegregates with a DNA haplotype of the apo B gene in an Idaho pedigree, with a maximum decimal logarithm of the ratio (LOD) score of 7.56 at a recombination rate of zero. Individuals carrying this haplotype had total cholesterol levels of 96 $\mathrm{mg} / \mathrm{dl}$, LDL cholesterol levels of $37 \mathrm{mg} / \mathrm{dl}$, triglycerides levels of $51 \mathrm{mg} / \mathrm{dl}$, and apo B levels of $38 \mathrm{mg} / \mathrm{dl}$. This study strongly suggests that apo $B$ mutations underlie hypobetalipoproteinemia, and demonstrates the power of the candidate gene approach in linkage analysis for unraveling genetic determinants in metabolic disorders of undefined etiology.
\end{abstract}

\section{Introduction}

Two inherited lipoprotein deficiency states, abetalipoproteinemia and hypobetalipoproteinemia (HBLP), ${ }^{1}$ share similar clinical and biological features in the homozygous form (1). Affected individuals suffer from fat malabsorption, ataxic neuropathy, atypical retinitis pigmentosa, and acanthocytosis. Chylomicrons, VLDL, and LDL are absent from plasma, and apo B, an obligatory constituent of these three lipid fractions, is not detectable immunologically. Only traces of triglycerides can be identified; cholesterol, essentially confined to the high density lipoprotein (HDL) fraction, typically has a concentration $<50 \mathrm{mg} / \mathrm{dl}$.

The distinction between these two clinical entities rests on the blood lipid profiles of parents, both of whom are obligate heterozygotes and free of clinical manifestations (1). Whereas parents of abetalipoproteinemia patients cannot be distinguished from normal subjects, parents of hypobetalipoproteinemia patients usually have low concentrations of VLDL and LDL, and therefore low plasma concentrations of triglycerides

Address reprint requests to Dr. Jean-Marc Lalouel, Howard Hughes Medical Institute, Wintrobe Building, 6th floor, University of Utah Medical Center, Salt Lake City, UT 84132.

Received for publication 20 July 1987 and in revised form 11 April 1988.

1. Abbreviations used in this paper: HBLP, hypobetalipoproteinemia; HDL, high density lipoprotein; LOD, decimal logarithm of the ratio; RFLP, restriction fragment length polymorphism.

J. Clin. Invest.

(C) The American Society for Clinical Investigation, Inc.

0021-9738/88/09/0847/05 $\$ 2.00$

Volume 82, September 1988, 847-851 and cholesterol, the latter best noted in the LDL fraction. No particular abnormality of the lipid particles or of their constituents has been identified for any lipid fraction (1). Investigations of LDL metabolism in such subjects have shown reduced synthesis and normal catabolic rates $(2,3)$. The molecular basis of this disorder is unknown; any alteration of apo B, lipoprotein assembly, and secretion could account for the clinical and biological manifestations.

Apo $B$ is the major protein constituent of the LDL particle and the ligand for the LDL receptor that clears these particles from the circulation. Recently cDNA and genomic clones of the apo $B$ genes have been isolated in several laboratories (4-8). Screening of random individuals with various restriction enzymes $(9,10)$, or comparison of DNA sequences in different subjects (11), have identified a number of DNA variants in the genomic region encoding the apo $B$ gene. We have characterized such DNA polymorphisms in a pedigree that includes 17 subjects with heterozygous HBLP. The cosegregation of HBLP with an apo B haplotype strongly suggests that this disorder results from mutations of the apo B gene.

\section{Methods}

Selection of subjects. In the course of family studies to identify genetic markers that affect lipoprotein levels and susceptibility to atherosclerosis, an asymptomatic 41-yr-old woman was found to have total cholesterol and triglyceride levels of 80 and $35 \mathrm{mg} / \mathrm{dl}$, respectively, whereas her LDL-cholesterol level was $19 \mathrm{mg} / \mathrm{dl}$. Her spouse and four of her seven offspring were normal, but three offspring had lipid profiles similar to their mother's. The initial analysis of this family, together with the mother's siblings and their living mother, motivated the extension of the pedigree, referred to as pedigree 635 . Extension was done by preliminary field analysis of total cholesterol levels on finger-prick specimens, with a portable blood chemistry analyzer ( Reflotron; Boehringer Mannheim Diagnostics, Indianapolis, IN), to ascertain other family lineages warranting further investigation.

Blood sampling and lipid and lipoprotein analysis. Blood samples were obtained in EDTA tubes for lipid analysis and in citrated tubes for DNA analysis, from 39 pedigree members who had been fasting for 12-16 h. Lipid and lipoprotein measurements were made on fresh, unfrozen plasma. Total cholesterol, lipoprotein cholesterol, and triglycerides were determined enzymatically using Boehringer Mannheim Biochemicals kits. HDL cholesterol was determined after VLDL and LDL were precipitated by the dextran sulfate method. LDL plus HDL cholesterol were determined on the infranatant after removal of VLDL cholesterol by airfuge ultracentrifugation (Beckman Instruments, Fullerton, CA). LDL cholesterol was determined by subtracting the HDL cholesterol value from the cholesterol in the infranatant. VLDL cholesterol was determined by subtracting the cholesterol in the infranatant from the total cholesterol. apo B concentrations were assayed by RIA with Ventrex kits (Ventrex Laboratories; Portland, ME). apo $\mathrm{E}$ phenotypes were determined by isolectric focusing, as described in reference 12 . 
Southern blot analysis. Two cloned segments of the apo B gene, pB8 and pB23, were prepared as described elsewhere (13). The whole plasmids were labeled to a high specific activity (14). From each pedigree member, $5 \mu \mathrm{g}$ of DNA, prepared as described previously (15), was digested with a 5- to 10-fold excess of restriction endonucleases Xba I, Eco RI, and Msp I (Boehringer Mannheim Biochemicals), electrophoresed in $\mathbf{0 . 7 \%}$ agarose gels, and transferred to nylon membranes in a basic transfer buffer (16). Membranes blotted with Eco RI- or Msp I-digested DNA were hybridized with ${ }^{32} \mathrm{P}$-labeled $\mathrm{pB} 8$, and membranes blotted with Xba I-digested DNA were hybridized with ${ }^{32} \mathrm{P}$-labeled pB23. The restriction fragment length polymorphisms (RFLPs) in the apo $B$ gene that can be detected in this manner have been described $(9$, 13). Prehybridization and hybridization were performed using the solutions and conditions described in reference 17.

Segregation and linkage analysis. The familial distribution of lipid measurements and apo B genotypes were analyzed with the PAP (18) and LINKAGE (19) computer programs. Because the available measurements might not allow the unambiguous identification of HBLP heterozygotes, quantitative measurements were anałyzed as such. An autosomal dominant mode of inheritance was assumed for the transmission of HBLP, as well as an arbitrarily low gepe frequency for the defective gene. It is assumed that the defective gene affects the mean value of the quantitative phenotypes among carriers and that, conditioned on the genotype at this locus, the quantitative phenotypes follow a multivariate distribution. The distribution of the phenotypes in the pedigree is expressed as a function of the unknown genotypic means and variance-covariances of the traits. The simultaneous segregation of the DNA markers at the apo $B$ locus is expressed as a function of the unknown recombination rate between the HBLP and the apo $B$ loci. The null hypothesis of independent segregation of lipid parameters and the apo B locus was tested by comparing the likelihood of the observations when the recombination fraction was fixed at 0.5 with that obtained when recombination was also estimated, other parameters being estimated in both casès. The decimal logarithm of the ratio thus obtained, or LOD score, is considered significant when it is $>3(20)$.

\section{Results}

Definition of apo B haplotypes. Xba I, Eco RI, and Msp I RFLP were determined for pedigree members. Linkage disequilibrium between the Msp I and Eco RI sites was such that Eco RI did not contribute additional genotypic information over Msp I genotypes. The Xba I polymorphism, however, allowed definition of the haplotypes necessary to track the inheritance of the apo B gene in this pedigree.
Analysis of the proband's nuclear family. In the family tree shown in Fig. 1, the proband is subject 34, her spouse is subject 33, and her 7 children are subjects 46-52. As reported in Table I, the HBLP phenotype segregated in this family; the proband and three of seven offspring had LDL cholesterol levels ranging between 19 and $36 \mathrm{mg} / \mathrm{dl}$, whereas her spouse and the other four offspring had LDL cholesterol levels ranging from 101 to $119 \mathrm{mg} / \mathrm{dl}$. Southern blot analysis revealed that all four HBLP subjects shared an apo B haplotype not found in their normal relatives. Within this nuclear family, linkage was suggested by a LOD score of 1.8 at a recombination rate of zero.

Analysis of the extended pedigree. The proband's mother, subject 10, did not carry the apo B haplotype that segregated with HBLP in this family. The mutant allele therefore was inherited through the dead father, subject 9 . His having had 11 siblings, however, offered the opportunity to detect the occurrence of HBLP in his relatives. The pedigree of Fig. 1 summarizes the branches that were ascertained as described in Methods.

Lipid, apo B, and DNA polymorphism determinations are reported in Table I. For the analysis, cholesterol and apo B measurements were adjusted for age and sex through regression parameters defined in previous studies (21). Because the distribution of triglyceride levels is highly skewed, a logarithmic transformation was applied before the analysis. Simultaneous segregation and linkage analysis, as described in Methods, were performed for each of the four available quantitative measurements. A metabolic disturbance affecting the lipoprotein fraction that contains apo B as a major constituent is likely to alter all four measurements. Three of them, total cholesterol, total triglycerides, and LDL cholesterol, were measured on all sampled subjects. As each parameter involves a measurement error, using them jointly as indicators of the underlying disturbance may increase the power to establish linkage between HBLP and the apo B gene. Results of joint analyses are reported in Table II.

Each of the measurements, except for triglycerides, supported with a LOD score $>3$ the hypothesis that the apo B DNA märker segregates with HBLP in this pedigree (Table II). The greatest support is obtained when all three lipid measurements were analyzed jointly; a LOD score of 7.56 for a recombination fraction of zero was then obtained. The odds of this observation arising by chance alone are $<10^{-7}$.

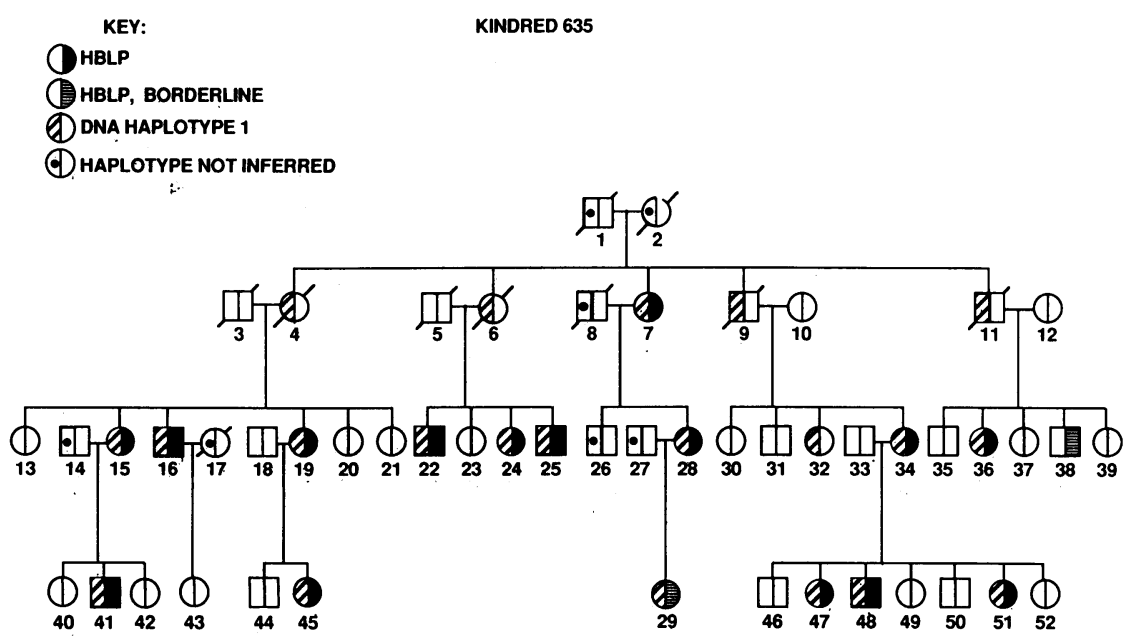

Figure 1. Abridged presentation of pedigree 635. Only the family branches that were ascertained through field survey are represented. Haplotype 1 consists of allele 1 with Xba I and allele 2 with Msp I. In some individuals, the familial segregation of the Xba I and Msp I polymorphisms did not permit unambiguous inference of haplotypes. When lipid values did not allow classification into HBLP with sufficient confidence, subjects were referred to as borderline. When the chromosomal distribution of the apo B Msp I and Xba I alleles could not be determined from the pedigree data, these individuals were identified by the designation "haplotype not inferred." 
Table I. Individual Data on Pedigree 635

\begin{tabular}{|c|c|c|c|c|c|c|c|c|c|c|c|}
\hline Id & Sex & Age & $\mathrm{CH}$ & TG & VLDL & LDL & HDL & apo B & E & Msp I & Xba I \\
\hline 7 & $\mathbf{F}$ & 93 & $75 \mathrm{~L}$ & 69 & 10 & $19 \mathrm{~L}$ & 46 & 27 & 33 & 12 & 11 \\
\hline 10 & $\mathbf{F}$ & 83 & 264 & 114 & 29 & 189 & 46 & 175 & 33 & 12 & 12 \\
\hline 12 & $\mathbf{F}$ & 80 & $164 \mathrm{~L}$ & $378 \mathrm{H}$ & 64 & $66 \mathrm{~L}$ & 34 & 94 & 43 & NA & 12 \\
\hline 13 & $\mathbf{F}$ & 76 & 232 & 213 & 95 & $95 \mathrm{~L}$ & 42 & NA & 22 & 22 & 22 \\
\hline 15 & $\mathbf{F}$ & 75 & $103 \mathrm{~L}$ & 145 & 21 & $37 \mathrm{~L}$ & 45 & NA & 32 & 22 & 12 \\
\hline 16 & $\mathbf{M}$ & 71 & $82 \mathrm{~L}$ & $49 \mathrm{~L}$ & 2 & $39 \mathrm{~L}$ & 41 & NA & 32 & 22 & 12 \\
\hline 19 & $\mathrm{~F}$ & 67 & $107 \mathrm{~L}$ & 159 & 35 & $36 \mathrm{~L}$ & 36 & NA & 32 & 22 & 12 \\
\hline 20 & $\mathbf{F}$ & 64 & 227 & $242 \mathrm{H}$ & 122 & $59 \mathrm{~L}$ & 46 & NA & 22 & 22 & 22 \\
\hline 21 & $\mathbf{F}$ & 63 & 220 & 126 & 32 & 138 & 50 & NA & 32 & 22 & 22 \\
\hline 22 & $\mathbf{M}$ & 71 & $108 \mathrm{~L}$ & $56 \mathrm{~L}$ & 14 & $46 \mathrm{~L}$ & 48 & 38 & 33 & 23 & 11 \\
\hline 23 & $\mathbf{F}$ & 68 & 268 & 166 & 74 & 157 & 37 & 171 & 43 & 13 & 11 \\
\hline 24 & $\mathrm{~F}$ & 67 & $134 \mathrm{~L}$ & 85 & 12 & $37 \mathrm{~L}$ & 85 & 31 & 43 & 23 & 11 \\
\hline 25 & $\mathbf{M}$ & 61 & $91 \mathrm{~L}$ & 98 & 7 & $45 \mathrm{~L}$ & 39 & 37 & 33 & 23 & 11 \\
\hline 26 & $\mathbf{M}$ & 63 & 160 & 226 & 45 & 87 & $28 \mathrm{~L}$ & 116 & 43 & 12 & 12 \\
\hline 28 & $F$ & 58 & $149 \mathrm{~L}$ & $44 \mathrm{~L}$ & 22 & $41 \mathrm{~L}$ & 86 & 39 & 44 & 22 & 12 \\
\hline 29 & $\mathrm{~F}$ & 34 & 135 & 67 & 20 & $60 \mathrm{~L}$ & 53 & 54 & 43 & 22 & 12 \\
\hline 30 & $\mathbf{F}$ & 62 & $341 \mathrm{H}$ & $241 \mathrm{H}$ & 60 & $242 \mathrm{H}$ & 39 & 175 & 32 & 22 & 22 \\
\hline 31 & $\mathbf{M}$ & 53 & $293 \mathrm{H}$ & 148 & 38 & $217 \mathrm{H}$ & 38 & NA & 32 & 22 & 22 \\
\hline 32 & $\mathbf{F}$ & 47 & 167 & 95 & 12 & 109 & 46 & 75 & 33 & 22 & 12 \\
\hline 33 & $\mathbf{M}$ & 42 & 174 & 95 & 8 & 119 & 43 & 90 & 33 & 12 & 12 \\
\hline 34 & $\mathbf{F}$ & 42 & $80 \mathrm{~L}$ & $35 \mathrm{~L}$ & 3 & $19 \mathrm{~L}$ & 58 & 18 & 32 & 22 & 12 \\
\hline 35 & $\mathbf{M}$ & 60 & 231 & 111 & 41 & 158 & 32 & 139 & 32 & NA & 12 \\
\hline 36 & $\mathbf{F}$ & 59 & $123 \mathrm{~L}$ & 68 & 14 & $56 \mathrm{~L}$ & 53 & 38 & 42 & 22 & 12 \\
\hline 37 & $\mathbf{F}$ & 57 & 248 & 59 & 14 & 178 & 56 & 154 & 33 & 12 & 12 \\
\hline 38 & $\mathbf{M}$ & 53 & $130 \mathrm{~L}$ & 101 & 17 & $74 \mathrm{~L}$ & 39 & 77 & 33 & 11 & 11 \\
\hline 39 & $\mathbf{F}$ & 41 & 167 & 90 & 14 & 101 & 52 & 84 & 33 & NA & 11 \\
\hline 40 & $\mathbf{F}$ & 47 & 195 & 151 & 35 & 98 & 62 & 105 & 33 & 22 & 22 \\
\hline 41 & $\mathbf{M}$ & 43 & $101 \mathrm{~L}$ & $48 \mathrm{~L}$ & 8 & $56 \mathrm{~L}$ & 37 & 41 & 33 & 22 & 12 \\
\hline 42 & $F$ & 40 & 238 & 162 & 46 & 159 & $33 \mathrm{~L}$ & 173 & 33 & 22 & 22 \\
\hline 43 & $F$ & 40 & 182 & 134 & 18 & 116 & 48 & 98 & 32 & 22 & 12 \\
\hline 44 & $\mathbf{M}$ & 49 & 225 & $609 \mathrm{H}$ & 75 & 125 & $25 \mathrm{~L}$ & 136 & 32 & 22 & 22 \\
\hline 45 & $\mathbf{F}$ & 45 & $87 \mathrm{~L}$ & $43 \mathrm{~L}$ & 15 & $40 \mathrm{~L}$ & $32 \mathrm{~L}$ & 36 & 33 & 22 & 12 \\
\hline 46 & $\mathbf{M}$ & 19 & 188 & $168 \mathrm{H}$ & 31 & 119 & 38 & 107 & 33 & 12 & 12 \\
\hline 47 & $\mathbf{F}$ & 18 & $82 \mathrm{~L}$ & $32 \mathrm{~L}$ & 9 & $20 \mathrm{~L}$ & 53 & 22 & 32 & 22 & 12 \\
\hline 48 & $\mathbf{M}$ & 17 & $109 \mathrm{~L}$ & $37 \mathrm{~L}$ & 7 & $22 \mathrm{~L}$ & $80 \mathrm{H}$ & 20 & 32 & 12 & 11 \\
\hline 49 & $\mathbf{F}$ & 14 & 165 & 113 & 9 & 105 & 41 & 85 & 33 & 22 & 22 \\
\hline 50 & $\mathbf{M}$ & 13 & 184 & 110 & 20 & 109 & 55 & 94 & 32 & 22 & 22 \\
\hline 51 & $\mathbf{F}$ & 10 & $95 \mathrm{~L}$ & 53 & 6 & $36 \mathrm{~L}$ & 53 & 34 & 33 & 12 & 11 \\
\hline 52 & $F$ & 7 & 167 & 97 & 25 & 101 & 41 & 98 & 33 & 12 & 12 \\
\hline
\end{tabular}

Total cholesterol $(\mathrm{CH})$, triglycerides (TG), cholesterol measurements in lipoprotein fractions (VLDL, LDL, and HDL) and apo B quantitation (apo B) are expressed in milligrams per deciliter. E stands for the apo E phenotype determined by isolectric focusing; Msp I and Xba I are two genotypes at the apo B locus. NA, not available. When LRC reference values are available, values below the 5 th $(\mathrm{L})$ and above the 95 th percentile $(\mathrm{H})$ are flagged.

To summarize the segregation and linkage evidence in a simple and descriptive manner, the estimated means and variance-covariances of the three lipid measurements were used to create a linear combination within each genotypic class. This procedure led to the definition of a compound variable for each individual assayed in the pedigree. For ease of presentation, all measurements were centered to the midpoint of the interval defined by the expected means of this compound in each genotypic class. Again, for descriptive purposes only, individuals could then be classified as HBLP or normal subjects, depending on whether they had or had not inherited the apo B haplotype that segregates with HBLP. The linkage evidence thus can be described approximately as reflected in Fig. 1. The expected distribution and the observed values for this linear combination are reported in Fig. 2. Note that although the cosegregation of HBLP and the apo B marker is clearly apparent, a few individuals seem not to have inherited HBLP jointly with the apo B marker. This indicates that unambiguous identification of heterozygotes cannot be achieved on the basis of these measurements alone. Analyzing the quantitative values rather than making a dichotomic classification before the analysis circumvented the issue of genotypic identification. 
Table II. Segregation and Linkage Analysis

of Hypobetalipoproteinemia in Pedigree 635

\begin{tabular}{lrrrcc}
\hline & \multicolumn{2}{c}{ Genotypic means } & & & \\
\cline { 2 - 4 } Variable(s) & Normal & Carrier & \multicolumn{1}{c}{ SD } & Recombination & LOD score \\
\hline (A) CH & 198.76 & 101.16 & 34.62 & 0.0 & 6.96 \\
$(B)$ LDL & 133.13 & 38.22 & 36.62 & 0.0 & 4.93 \\
(C) TG & 135.50 & 52.46 & 40.50 & 0.0 & 2.21 \\
$(D)$ apo B & 121.62 & 38.26 & 28.32 & 0.0 & 4.48 \\
(E) CH & 190.05 & 96.33 & 31.66 & 0.0 & 7.56 \\
TG & 4.91 & 3.93 & 0.49 & & \\
LDL & 118.14 & 36.68 & 34.63 & & \\
\hline
\end{tabular}

$\mathrm{CH}$, total cholesterol; TG, triglycerides levels; LDL, LDL cholesterol; $\mathrm{SD}$, standard deviation within genotypic distribution. $\mathrm{CH}$ alone was used in model $A$, whereas all three measurements were used in model $B$. Genotypic means, variance-covariances, and recombination rate between a postulated HBLP locus and apo B were jointly estimated. Logarithmic transformation was applied to triglycerides in the analysis.

\section{Discussion}

Cosegregation of hypobetalipoproteinemia with a particular allele of the apo B gene was demonstrated in a pedigree with a dominant pattern of inheritance of low LDL cholesterol levels. A defect of the apo B gene is probably responsible for the

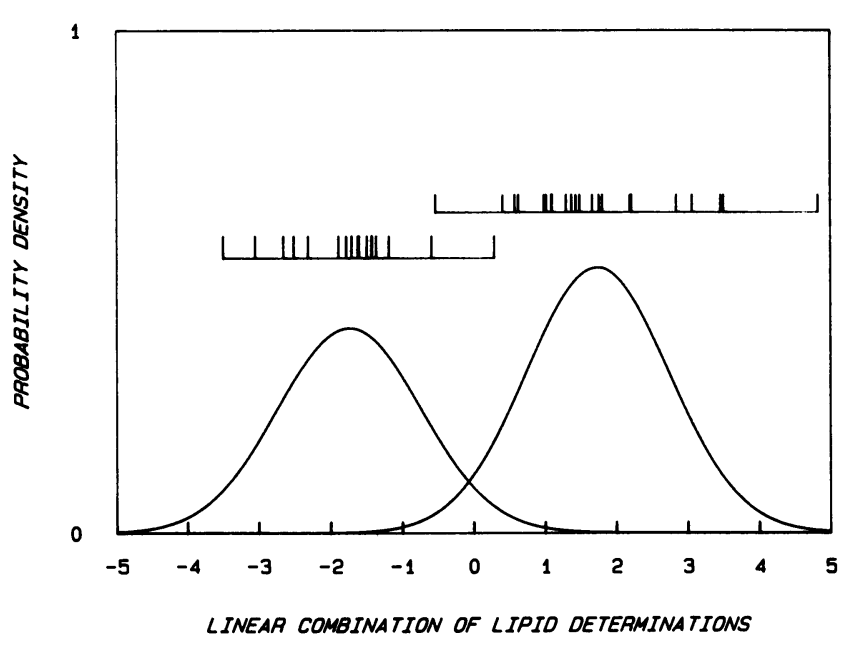

Figure 2. The expected distribution of a linear combination of total cholesterol, the natural logarithm of triglycerides, and LDL-cholesterol based on the estimates of Table II, model $E$. Genotypic distributions were standardized to unit variance and the scale was centered to the midpoint of the interval between genotypic means. The same transformation was applied to the individual data of Table I, and the individual scores are reported in the figure. The lower bar diagram documents the values of this index among individuals carrying the apo B haplotype that segregates with HBLP; the upper diagram reports the corresponding values among individuals who did not exhibit this haplotype. The highest value among carriers was found in individual 32; the lowest value among subjects not carrying the haplotype was found in individual 38. Both would have been misclassified if a cut-off point had been defined before the analysis. occurrence of the lipid disorder in this pedigree. In a recent study, individuals in one family with HBLP were found to have low amounts of a small apo B protein, called B-37, in their plasma. This is presumably due to a mutation in the apo $B$ gene that results in a truncated, unstable, or poorly synthesized protein $(22,23)$. In an investigation of two homozygous HBLP patients, it was shown that apo B mRNA levels and apo $B$ levels were sharply reduced in liver cells (24). The results of these studies are compatible with the notion that mutations in the apo B gene cause HBLP.

17 of the 39 sampled individuals carried the apo B haplotype that segregates with HBLP. One of these carriers, subject 32, exhibited almost normal lipid levels: total cholesterol of $167 \mathrm{mg} / \mathrm{dl}$, LDL cholesterol levels of $109 \mathrm{mg} / \mathrm{dl}$, triglyceride levels of $95 \mathrm{mg} / \mathrm{dl}$, and apo B concentrations of $75 \mathrm{mg} / \mathrm{dl}$. This 47-yr-old woman is the sister of our initial proband, subject 34 . Two other siblings, subjects 30 and 31 , and the mother of those two siblings, subject 10 , had high levels of total cholesterol or LDL cholesterol. Indeed, a pedigree branch of relatives of subject 10 , with several cases of familial hypercholesterolemia and premature myocardial infarction, had led to the ascertainment of the HBLP proband, subject 34 . Subject 32 conceivably carries two mutations at either one locus or at two different loci, each exerting an opposite effect on cholesterol metabolism.

One person who did not carry the HBLP haplotype, subject 38, had lipid values similar to those obtained in the mildest case of HBLP, subject 29. Unambiguous classification of HBLP based solely on lipid profiles, or on LDL cholesterol alone, is therefore not possible in this pedigree. Furthermore, subject 20, who does not carry the HBLP haplotype, had a total cholesterol level of $227 \mathrm{mg} / \mathrm{dl}$, a triglyceride level of 242 $\mathrm{mg} / \mathrm{dl}$, a VLDL cholesterol level of $122 \mathrm{mg} / \mathrm{dl}$, an LDL cholesterol level of $59 \mathrm{mg} / \mathrm{dl}$, and an HDL cholesterol level of 46 $\mathrm{mg} / \mathrm{dl}$. This subject presents the E2/2 phenotype at the apo E locus, and his lipid profile is characteristic of type III hyperlipoproteinemia. Defective apo $\mathrm{E}$ is thought to result in low LDL cholesterol levels by inhibiting the normal progression from VLDL to intermediate density lipoproteins and to LDL, and/or by failing to deliver enough intermediate density lipoproteins and chylomicron remnants to the liver to down-regulate hepatic LDL receptors (25). The resultant up-regulation of LDL receptors is thought to cause a decrease in plasma LDL cholesterol levels. Various common genetic variants and environmental determinants that affect lipid levels in defined pedigrees, constitute a difficult challenge for genetic investigators.

In summary, through linkage analysis, we have presented strong evidence that a defect in the apo B gene is responsible for the occurrence of HBLP in an Idaho pedigree. The actual mutation involved remains to be identified. Our study also illustrates the power of the candidate gene approach for investigating the etiology of complex disorders of metabolism.

\section{Acknowledgments}

This work was supported in part by grants from the National Institutes of Health (HL-21088-11, HL-33714, HL-32435, and HL-36461) and by general support from Pew Trusts to Dr. Breslow and the Howard Hughes Medical Institute. Jan L. Breslow is an Established Investigator of the American Heart Foundation; Ray White and Jean-Marc Lalouel are Investigators of the Howard Hughes Medical Institute. 


\section{References}

1. Herbert, P. N., G. Assmann, A. M. Gotto, and D. S. Fredrickson. 1983. Familial lipoprotein deficiency: abetalipoproteinemia, hypobetalipoproteinemia, and Tangier disease. In The Metabolic Basis of Inherited Disease, 5th ed. J. B. Stanbury, J. B. Wyngaarden, D. S. Fredrickson, J. L. Goldstein, and M. S. Brown, editors. McGraw-Hill Book Co., New York. 587-621.

2. Levy, R. I., T. Langer, A. M. Gotto, and D. S. Fredrickson. 1970. Familial hypobetalipoproteinemia, a defect in lipoprotein synthesis. Clin. Res. 18:539a. (Abstr.)

3. Sigursson, G., A. Nicoll, and B. Lewis. 1977. Turnover of apolipoprotein B in two subjects with familial hypobetalipoproteinemia. Metab. Clin. Exp. 26:25-31.

4. Huang, L.-S., S. C. Bock, S. I. Feinstein, and J. L. Breslow. 1985. Human apolipoprotein B cDNA clone isolation and demonstration that liver apolipoprotein B mRNA is 22 kilobases in length. Proc. Natl. Acad. Sci. USA. 82:6825-6829.

5. Knott, T. J., R. J. Pease, L. M. Powell, S. C. Wallis, S. C. Rall, Jr., T. L. Innerarity, B. Blackhart, W. H. Taylor, Y. Marcel, R. Milne, D. Johnson, M. Fuller, A. J. Lusis, B. J. McCarthy, R. W. Mahley, B. Levy-Wilson, and J. Scott. 1986. Complete protein sequence and identification of structural domains of human apolipoprotein B. $\mathrm{Na}$ ture (Lond.). 323:734-738.

6. Chen, S.-H., C.-Y. Yang, P.-Y. Chen, D. Setzer, M. Tanimura, W.-H. Li, A. M. Gotto, Jr., and L. Chan. 1986. The complete cDNA and amino acid sequence of human apolipoprotein B-100. J. Biol. Chem. 261:12918-12921.

7. Blackhart, B. D., E. M. Ludwig, V. R. Pierotti, L. Caiati, M. A. Onash, S. C. Wallis, L. Powell, R. Pease, T. J. Knott, M.-L. Chu, R. W. Mahley, J. Scott, B. J. McCarthy, and B. Levy-Wilson. 1986. Structure of the apolipoprotein B gene. J. Biol. Chem. 261:15364-15367.

8. Knott, T. J., S. C. Wallis, L. M. Powell, R. J. Pease, A. J. Lusis, B. Blackhart, B. J. McCarthy, R. W. Mahley, B. Levy-Wilson, and J. Scott. 1986. Complete $\mathrm{cDNA}$ and derived protein sequence of human apolipoprotein B-100. Nucleic Acids Res. 14:7501-7502.

9. Priestly, L., T. Knott, S. Wallis, L. Powell, R. Pease, A. Simon, and J. Scott. 1985. RFLP for the human apolipoprotein B gene. $\mathrm{Nu}$ cleic Acids Res. 13:6789-6793.

10. Huang, L.-S., D. A. Miller, G. A. P. Bruns, and J. L. Breslow. 1986. Mapping of the human ApoB gene to chromosome $2 p$ and demonstration of a two-allele restriction fragment length polymorphism. Proc. Natl. Acad. Sci. USA. 83:644-648.

11. Knott, T. J., S. C. Wallis, R. J. Pease, L. M. Powell, and J. Scott. 1986. A hypervariable region 3 ' of the human apolipoprotein B gene. Nucleic Acids Res. 14:9215-9216.

12. Warnick, G. R., G. Mayfield, J. J. Albers, and W. R. Hazzard.
1979. Gel isoelectric focusing method for specific diagnosis of familial hyperlipoproteinemia Type 3. Clin. Chem. 25:279-284.

13. Hegele, R. A., L.-S. Huang, P. N. Herbert, C. B. Blum, J. E. Buring, C. H. Hennekens, and J. L. Breslow. 1986. Apolipoprotein B: gene DNA polymorphisms associated with myocardial infarction. $N$. Engl. J. Med. 315:1509-1515.

14. Feinberg, A. P., and B. Vogelstein. 1983. A technique for radiolabeling DNA restriction endonuclease fragments to high specific activity. Anal. Biochem. 132:6-13.

15. Bell, G., J. Karam, and W. Rutter. 1981. Polymorphic DNA region adjacent to the $5^{\prime}$ end of the human insulin gene. Proc. Natl. Acad. Sci. USA. 78:5759-5763.

16. Reed, K. C., and D. A. Mann. 1985. Rapid transfer of DNA from agarose gels to nylon membranes. Nucleic Acids Res. 13:72077221.

17. Cavenee, W., R. Leach, T. Mohandas, P. Pearson, and R. White. 1984. Isolation and regional localization of DNA segments revealing polymorphic loci from human chromosome 13. Am. J. Hum. Genet. 36:10-24.

18. Hasstedt, S. J., and P. E. Cartwright. 1981. PAP: pedigree analysis package. Revision 2, Technical Report No. 13. Department of Medical Biophysics and Computing, University of Utah, Salt Lake City, UT.

19. Lathrop, G. M., J.-M. Lalouel, C. Julier, and J. Ott. 1984. Strategies for multilocus linkage analysis in humans. Proc. Natl. Acad. Sci. USA. 81:3443-3446.

20. Morton, N. E. 1955. Sequential tests for the detection of linkage. Am. J. Hum. Genet. 7:277-318.

21. Williams, R. R., S. J. Hasstedt, D. E. Wilson, K. O. Ash, F. F. Yanowitz, G. E. Reiber, and H. Kuida. 1986. Evidence that men with familial hypercholesterolemia can avoid early coronary death: analysis of 77 gene carriers in four Utah pedigrees. JAMA (J. Am. Med. Assoc.). 255:219-224.

22. Young, S. G., S. J. Bertics, L. K. Curtiss, and J. L. Witztum. 1987. Characterization of an abnormal species of apolipoprotein B, Apolipoprotein B-37, associated with familial hypobetalipoproteinemia. J. Clin. Invest. 79:1831-1841.

23. Young, S. G., S. J. Bertics, L. K. Curtiss, B. W. Dubois, and J. L. Witzum. 1987. Genetic analysis of a kindred with familial hypobetalipoproteinemia. J. Clin. Invest. 79:1842-1851.

24. Ross, R. S., R. E. Gregg, S. W. Law, J. C. Monge, S. M. Grant, K. Higuchi, T. J. Triche, J. Jefferson, and H. B. Brewer, Jr. 1988. Homozygous hypobetalipoproteinemia: a disease distinct from abetalipoproteinemia at the molecular level. J. Clin. Invest. 81:590-595.

25. Weintraub, M. S., S. Eisenberg, and J. L. Breslow. 1987. Different patterns of postprandial lipoprotein metabolism in normal, type IIa, type III, and type IV hyperlipoproteinemic individuals. J. Clin. Invest. 79:1110-1119. 